\title{
JUNTOS INEVITAVELMENTE “NA TERRA QUE NOS TORNA TÃO FEROZES” (DANTE) NO TEMPO DO COVID $19^{8}$
}

\section{INEVITABLY TOGETHER “ON THE LAND THAT MAKES US SO FIERCI” (DANTE) IN THE TIME OF COVID 19}

\author{
Augusto Ponzio 9 \\ Mary Sellani ${ }^{10}$ \\ tradução de Marisol Barenco ${ }^{11}$ \\ Revisão da tradução Cecília Maculan Adum ${ }^{12}$
}

\section{Resumo}

O presente texto trata-se de uma entrevista, inédita na Itália, concedida pelo professor Augusto Ponzio à professora Mary Sellani, jornalista italiana. Na entrevista, o professor Ponzio reflete sobre as questões atuais com as quais a humanidade se defronta, incluindo a problemática da pandemia do Covid 19, revelando a atualidade do pensamento de Emmanuel Levinas e sua compreensão da necessidade de criticarmos as ideias de identidade, de medo do outro e fechamento em totalidades identitárias. Ao contrário, nos convida a voltarmos nossa atenção para as ideias e práticas que privilegiam as noções de alteridade, de responsabilidade sem álibi pelo outro e de não indiferença à humanidade. Uma ética de transformação do mundo, sob os valores do estarmos juntos, inevitavelmente.

Palavras-chave: Emmanuel Levinas. Alteridade. Juntos.

\section{Abstract}

This text is an interview - unprecedented in Italy - given by Augusto Ponzio to the Italian researcher Mary Sellani. In this interview, Ponzio reflects on the current issues the humanity is facing, including the Covid pandemic 19's problem, revealing the relevance of Emmanuel Levinas' thinking and his understanding about the need to criticize the identity' ideas, the fear of others and the closure in identity totalities. Instead, he invites us to turn our attention to the ideas and practices that privilege the otherness's notion and responsibility without alibi for the other and non-indifference to the humanity. A world's ethics transformation, under the values of being together, inevitably.

\footnotetext{
${ }^{8}$ Entrevista a Augusto Ponzio por Mary Sellani, inédita na Itália.

${ }^{9}$ Augusto Ponzio é professor ordinário de Filosofia e Teoria dei linguaggi e Professor emérito, ensinou Filosofia da Linguagem e Linguística geral na Università di Bari "Aldo Moro". Estuda e publica sobre Filosofia da Linguagem, Semiótica e Tradução, dentre outros temas, dedicando-se à filosofia de Emmanuel Levinas, Mikhail Bakhtin, Roland Barthes, dentre outros. E-mail: augustoponzio@libero.it Telefone: +393701387991 ORCID https://orcid.org/0000-0001-8073-7675.

10 Jornalista e colaboradora de periódicos como l'Avanti!, II Mattino, La Gazzetta del Mozzogiorno. Atualmente colabora con as revistas "EspressoSud", de Nocola Apollonio, com "Contrappunti", de Franco Chieco e com "Nelmese" de Alessio Rega.

${ }^{11}$ Marisol Barenco é professora associada na Faculdade de Educação da Universidade Federal Fluminense. Coordena o Grupo Atos UFF, onde realiza coletivamente estudos e pesquisas a partir da filosofia da linguagem do Círculo de Bakhtin. E-mail: sol.barenco@gmail.com Telefone: +552126292664 ORCID: https://orcid.org/0000-0002-9341-0230.

${ }^{12}$ Cecília Maculan Adum.
} 


\section{RevistAleph}

Keywords: Emmanuel Levinas. Otherness. Together.

\section{Introdução}

Um possível ponto de partida para reconstruir, nesta entrevista, o percurso de pesquisa de Augusto Ponzio - Professor emérito de Filosofia e Teoria das Linguagens na Università degli Studi di Bari e Docente de Linguística geral na Carlo Bo di Bari, de 2017/18 - pode ser o seu mais recente livro, Con Emmanuel Levinas. Alterità e Identità (Mimesis, 338 páginas), publicado em outubro de 2019, e no qual ele revisita o pensamento de Emmanuel Levinas (Kaunas, 1906 - Paris, 1995). Seu itinerário de estudo iniciou-se justamente pela leitura de uma obra fundamental de Levinas, Totalité et infini [Totalidade e Infinito] (1961), quando, a partir da primeira metade dos anos 1960, começou a trabalhar em sua tese de graduação em Filosofia (graduou-se em 1966), intitulada La relazione interpersonale, orientado pelo professor Giuseppe Semerari (1922-1996), então professor ordinário de Filosofia teórica e encarregado de Filosofia moral na Facoltà di Lettere e Filosofia dell'Università degli Studi di Bari.

Esse seu livro de 2019, Con Emmanuel Levinas. Alterità e Identità, é o atual ponto de chegada de um caminho que, partindo de Levinas, leva a Levinas; um caminho que, porém, não tem a forma de um círculo, e sim de uma espiral, já que não se trata de repetição, mas de um recomeçar, sempre de novo, de uma re-escritura; uma espécie, em suma, de eterno retorno de uma paixão intelectual sempre viva e reatualizada por contínuas reflexões sobre essa importante figura da filosofia do século XX, à luz dos acontecimentos que se sucederam até a atual configuração do mundo, após a chamada "globalização". Uma reflexão não interrompida, ainda que essa não tenha excluído a escuta de outras palavras, como as de Bakhtin, Kiekegaard, Peirce, Marx, Blanchot, Bataille, Barthes, Kristeva, Rossi Landi, Schaff, Sebeok... e de seu próprio professor, Giuseppe Semerari.

O itinerário especulativo de Levinas começa pelo pensamento de Husserl e de Heidegger, pela Bíblia e pelo Talmud, pela filosofia da Grécia antiga e pela grande literatura russa, para colocar em discussão as próprias categorias do pensamento ocidental (sujeito, identidade, pertença, consciência intencional, ser isso, ser aquilo: a "tumescência do eu sou"), não só no âmbito específico da pesquisa filosófica contemporânea, mas também na 


\section{RevistAleph}

pesquisa de um sentido da vida não reduzível ao oferecido pelo Mundo, pela História, pela Economia, e pela Política, assim como se configuram na nossa época.

"Atri nan limita la libertà dell ibo chiamandola alla respon sabiità, la instaura e la giustifica"

Emmanuet tevinas,

Le delimitazioni, di ardine etico-normativo, givuridioo e pol ifico dellla responsabiilta individuale le legei dello scambio eguale, le funzioni fis sate da i rualie da lla posizione sociale, le distinzioni sancite dalla legege fra identitata indwduali, ciascuna con la propria stera di iberta e di impu-

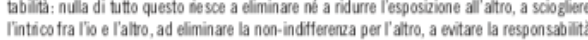
senza alibi nei suai contronti.

Enmanod Lovess Kaunas in Ltuania, 1906 - Pargi 1995)

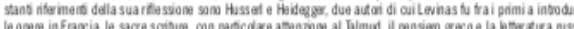

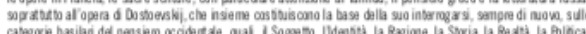

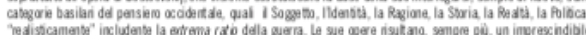

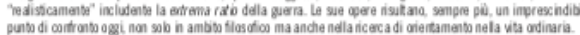

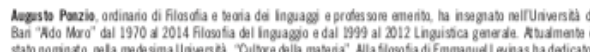

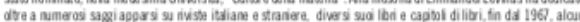

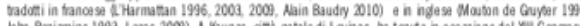

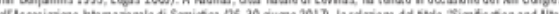

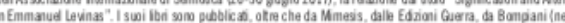

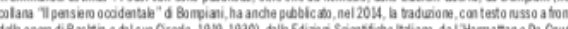

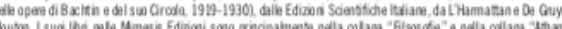

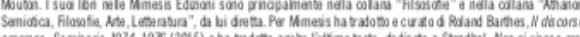

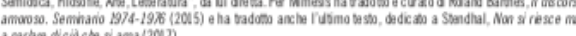

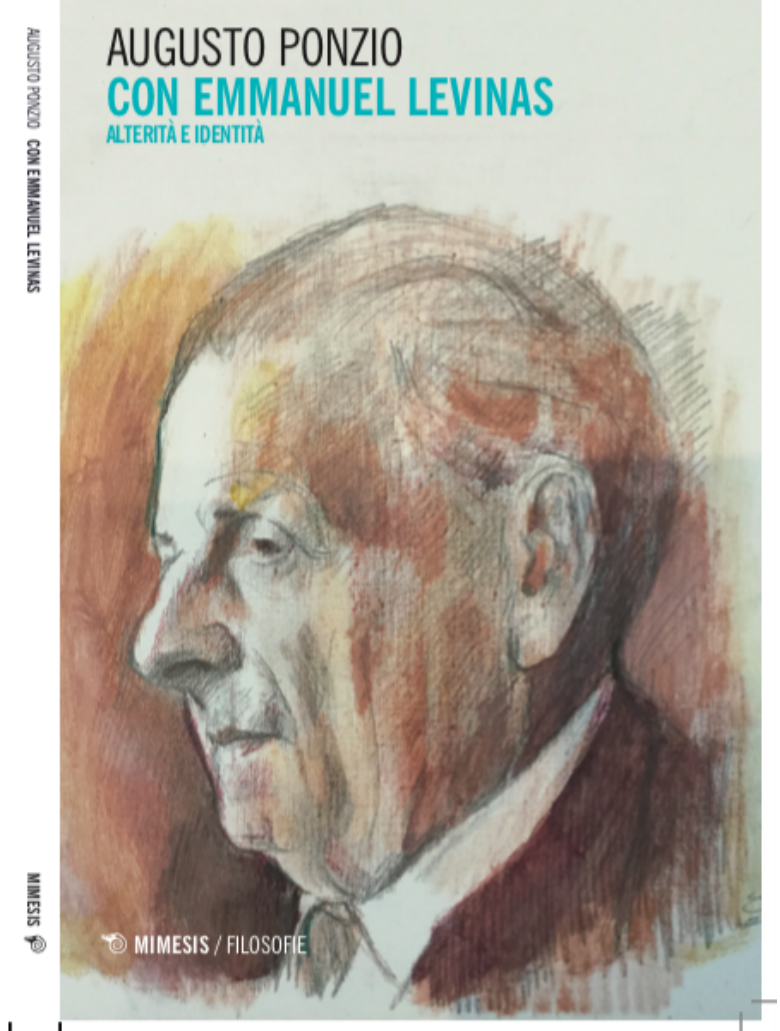

Figura 1 - Augusto Ponzio, Con Emmanuel Levinas. Alterità e identità, 2019.

Fonte: Copyright do autor.

Mary Sellani: Professor Ponzio, para retomar, então, o fio da reflexão, iniciemos pelo deslocamento do discurso filosófico tradicional operado por Levinas na dimensão da alteridade contra a ideologia dominante da identidade. Cada vez mais, vemos como, no nosso mundo globalizado, os chamados direitos humanos são substancialmente os direitos da identidade, como mostra Levinas em um ensaio de 1985, com o particularmente eloquente título Les droits de l'homme et les droits d'autrui [Os direitos do homem e os direitos dos outros], posteriormente publicado no livro Hors Sujet (1987, tr. it. de F. P. Ciglia, Fuori dal Soggetto, Marietti, 1992), no qual mostra que, dos chamados direitos humanos (enquanto, de fato, direitos da Identidade, do Eu, do Mesmo, da Pertença, da Comunidade), ficam de fora os direitos dos outros. A questão da identidade é central na reflexão de Levinas: identidade contraposta a alteridade, identidade que, cada vez mais entrincheirada na sua defesa, cada vez mais desconhece e viola os direitos dos outros. Devemos dizer que, 


\section{RevistAleph}

portanto, para que os direitos dos outros sejam reconhecidos e respeitados, é preciso uma nova concepção do humanismo?

Augusto Ponzio: Sim, é verdade, a questão da identidade deve ser levada seriamente em consideração. Dedicamos a essa questão também, eu e Susan Petrilli, o livro publicado em dezembro de 2019 na coleção "Athanor. Semiotica, filosofia arte, letteratura", coordenada por mim (Mimesis), intitulada justamente Identità e Alterità [Identidade e Alteridade], e também aqui toma a reflexão levinasiana como marco direcionador Do ensaio de Levinas que você recordou, Les droits de l'homme et les droits d'autrui, retomamos o título, no livro sucessivo da mesma coleção (Mimesis, 2020), Diritti umani e diritti altrui [Direitos humanos e direitos dos outros]: um volume que foi uma coletânea, organizado por Susan Petrilli, do qual participam também os professores de Ciências Políticas e de Direito Gaetano Dammacco, Nico Perrone, Paolo Stefanì, Bruno Veneziani e Ugo Villani, da Università di Bari, e o Prof. Mario Ricca, da Università di Parma. Há também um ensaio do, muito querido por todos nós, Vitilio Masiello (professor emérito de Literatura italiana), publicado originariamente em 2008, sobre o direito do trabalho na literatura entre os séculos XVIII e $X X$.

A identidade é a categoria dominante da razão ocidental. Ela se rege e se afirma com base na indiferença em relação ao outro, com o diverso, com o não pertencente. Se levarmos em consideração nossas relações enquanto seres humanos, todos podemos ser incluídos no grande conjunto do gênero humano (e, todavia, também a respeito disso, há sempre "outros" que são excluídos enquanto "desumanos" - o que justifica tomadas de posições, remédios e intervenções, aí compreendidas as "guerras humanitárias"), mas, ao mesmo tempo, somos distintos em outros conjuntos, como os do gêneros sexuais (gender), da idade, da nação, da comunidade, da língua, da religião, da etnia, da cor da pele etc.

Mas é realmente verdade que aquilo que nos caracteriza como vivos é a pertença a um conjunto, a um coletivo, a um grupo? A respeito da unidade, da comunidade, da pertença, da identidade, as quais, apesar da incomparabilidade, da unicidade de cada um, nos tornam intercambiáveis e nos reúnem em um mesmo conjunto, para Levinas há um outro modo de ver as coisas. No lugar da pluralidade ("Cidades plurais": o plural é sempre o representar-se do mesmo), deve ser reconhecida a multiplicidade e, com essa, a diversidade; ao invés da referência ao indivíduo - que, como tal, sempre faz parte de um 


\section{RevistAleph}

conjunto - o reconhecimento da singularidade, da unicidade de cada um, da irrepetibilidade, insubstituibilidade, não-acomunalidade, isto é, o próprio ser fora do gênero, sui generis.

Mas cuidado: a singularidade, a insubstituibilidade, a unicidade não é uma propriedade do sujeito em si mesmo (como sustentava Max Stirner em L'unico e la sua proprietà [O único e a sua propriedade]), mas a consequência de uma responsabilidade não delegável de cada um em relação ao outro na sua alteridade de outro. Por isso, ao invés de proximidade identitária, de proximidade como vizinhança, Levinas fala de uma proximidade sem defesa, sem limites, proximidade entre diversos, entre distantes. A proximidade ao outro é responsabilidade pelo outro. Proximidade significa a minha responsabilidade não delegável. É essa a minha unicidade, o meu ser único, o único para o outro: o meu ser suporte para a pesada carga da alteridade.

A alteridade na exposição face a face, isto é, fora dos escafandros identitários, das casacas e dos processos de pertença, não é mais a alteridade relativa dos papéis, das funções, das tarefas, das diversas formas de exercício do poder, das representações, dos álibis, não é alteridade relativa, mas alteridade absoluta.

A paz preventiva (essa é uma expressão de Levinas), a liberação do mundo em relação à guerra, que não é alcançável fazendo guerra à guerra através da "guerra preventiva", é o reconhecimento da proximidade inevitável ao outro como responsabilidade inevitável pelo outro. Outro autor que me é muito caro, Mikhail Bakhtin, de quem publiquei uma coletânea de textos junto aos textos do seu chamado Círculo (Michail Bachtin e il Suo Circolo, Opere 1919-1930, Bompiani, 2014), dizia: "Se interpretamos a nossa vida inteira como representação, nos tornamos impostores".

Mary Sellani: Por que o sistema da comunicação global e da produção mundializada, segundo Levinas, não pode incluir a migração?

Augusto Ponzio: Eu diria, ao contrário, que não se pode excluí-la. A migração é um problema do nosso tempo, inerente à globalização. Antes, falava-se de imigração, que era o deslocamento de um certo número (concordado) de pessoas de um país a outro. Ao contrário, a migração de hoje é incontrolável, como é incontrolável a migração das 


\section{RevistAleph}

andorinhas, de outros animais, dos "vírus" (a difusão do Corona vírus atesta o envolvimento mundial - devido à globalização - em relação ao problema da covid-19).

Da não-indiferença pelo outro à diferença e à relativa indiferença: esse é o percurso através do qual a identidade se constitui e se delineia. Por consequência, aquilo que nos diz respeito é progressivamente reduzido àquilo que diz respeito aos interesses da identidade, e tal redução encontra a justificação na condição da responsabilidade limitada garantida por álibi. Mas, quanto mais nos liberamos da condição de medo pelo outro, mais aumenta, até a exasperação, o medo do outro. Hoje, o medo do outro está no auge do paroxismo. Assim, a defesa da identidade diante do inevitável fenômeno da migração dá lugar às diversas manifestações de racismo.

Umberto Eco havia previsto isso desde as suas "Bustine di Minerva" (que eram artigos semanais publicados no jornal "Espresso") de 01-04-1990 e de 15-04-1990 (e, depois, por sua gentil concessão, no volume 4, de 1993, Migrazioni, da nossa série anual "Athanor. Semiótica, filosofia, arte, letteratura"), onde pela primeira vez, que eu saiba, foi estabelecida a distinção entre "imigração" e "migração". Em Migrazioni e intolleranza [Migrações e intolerância], uma coletânea de seus escritos recentemente publicada (La nave di Teseo, 2019), encontramos essa enunciação que é oportuno recordar aqui: “Eliminar o racismo não quer dizer mostrar ou convencer-se de que os Outros não são diversos de nós, mas compreender e aceitar a sua diversidade".

A comunidade não pode ser uma comunidade fechada. Deveria ser dito comunanza [comunalidade], onde o final proveniente de antia ou de entia, indica movimento, abertura, e deveria ser natural entender o extra, em "extracomunitário" (de modo a reter essa qualificação), como aquilo que plenamente, maximamente torna a comunidade um viver juntos.

Mary Sellani: Em que sentido a filosofia de Levinas se abre a uma nova visão da filosofia da linguagem, como se vê de modo evidente a partir de sua obra mais famosa, Totalité ed infini, na qual toda a tradição filosófica ocidental é colocada em discussão, pondo no centro da reflexão o primado da ética?

Augusto Ponzio: O primeiro movimento do eu é que esse sempre tem necessidade de justificar-se diante do outro. E a identidade - mais precisamente a pertença a uma identidade - é o meio prevalente de justificação do eu. O primeiro caso do eu, observa 


\section{RevistAleph}

Levinas, não é o nomitativo, mas o acusativo. A verdadeira questão, ele diz, não é a colocada por Martin Heidegger, "Por que o ser, e não o nada?", mas a pergunta colocada pelo outro ao eu: "Por que você está lá, naquela situação, naquele lugar, naquelas condições favoráveis, e eu não?" O recurso à identidade permite que eu me justifique, permite encontrar uma explicação, encontrar as motivações que demonstram o direito às minhas vantagens. A identidade é, portanto, um meio para se colocar a consciência em paz, para se colocar dentro de uma totalidade (como a Comunidade Europeia, a italianidade) que sirva de garantia e distinga quem tem direito a fazer parte dela e quem não. Mas o outro é aquele que, apesar de todos os esforços para encontrar justificações e rejeições por parte do eu, não está, por sua vez, dentro de alguma das totalidades (quaisquer que sejam) às quais o eu gostaria de relegá-lo. O outro não se deixa agarrar, classificar, etiquetar, prender, ele foge inevitavelmente.

A principal modalidade de perceber o outro, a partir da qual nasce a necessidade da justificação, é a "má consciência". Através do expediente do recurso à identidade diferente, aos diferentes direitos em relação ao outro, o eu consegue passar da difícil condição de "má consciência" àquela da "boa consciência", da situação de envolvimento e não indiferença à da indiferença. Mas é um engano, para si mesmo, antes de tudo.

A relação ética, no sentido em que Levinas utiliza essa expressão, diz respeito ao corpo e à palavra. O corpo e o seu emaranhado ético pressupõem que a palavra diga antes de tudo um contato, um envolvimento. O corpo permite que o dizer seja significativo e independente do dito. O aspecto corpóreo da palavra - a voz, o seu timbre, a escuta, o contato - não se reduz à sua função informativa, cognitiva, pragmática, mas constitui, ao contrário, seu pressuposto, é a sua capacidade de transcender o dito, é palavra humana.

Mary Sellani: O que Levinas quer dizer quando critica a nossa sociedade como "sociedade do conhecimento"?

Augusto Ponzio: Trata-se de uma crítica ante litteram. Encontramos essa expressão no Libro bianco su insegnare e apprendere [Livro branco sobre ensinar e aprender] (1995) da Comissão Europeia, texto basilar no redesenho, na Europa, do estudo e do ensino. A "sociedade do conhecimento", a knowledge society, baseia-se na ideologia segundo a qual a posição de cada um no espaço do saber e da competência é decisiva, ou seja, uma 


\section{RevistAleph}

sociedade na qual se faz com as relações inter-humanas dependam dos conhecimentos e das competências de cada um - melhor "todos", que faz bem a eliminação da singularidade, da alteridade - da contribuição, da funcionalidade de todos para as competências, para a produtividade e para a competitividade global. Esse modo de entender e promover as relações é a característica constitutiva da realidade social atual da comunicação-produção.

Mary Sellani: Portanto, a relação com o outro precede o saber.

Augusto Ponzio: Para Levinas e com Levinas, não se pode reduzir a relação interpessoal a uma relação de conhecimento. Na base da comunicação está o dar acolhimento ao interlocutor, está a relação com o outro como rosto, na sua nudez de rosto, como alteridade, como pessoa, como finalidade em si, fora dos papéis, da posição social, das trocas, do interesse, do lucro, da produtividade. A relação com o outro como expressão e como rosto não está subordinada ao conhecimento, à competência, à funcionalidade, não pode ser finalizada nesse sentido.

Mary Sellani: No seu ensaio de 1935, intitulado De l'evasion, Levinas introduz a necessidade de escapatória do ser no coração mesmo da filosofia...

Augusto Ponzio: Com a reflexão sobre a necessidade de evasão, Levinas coloca em discussão a aceitação do ser-assim do mundo e das coisas como fato completo e a consequente convicção da impossibilidade ou incapacidade de sair dele. "Toda civilização", ele diz, "que aceita o ser, o desespero trágico que envolve e os crimes que justifica, merece o nome de bárbara". Com o conceito de "evasão", Levinas introduz a categoria de excedência; essa necessidade indica justamente a possibilidade de transcendência (nesse sentido, ele fala de "metafísica" - termo retomado por Jacques Derrida já no título do ensaio dedicado à filosofia de Levinas, "Violência e metafísica", incluído em La scrittura e la differenza [A escritura e a diferença], de 1967) no que diz respeito à incômoda perspectiva da identidade do ser, do corpo pregado na máscara da identidade.

No ensaio de 1935, Levinas propõe uma fenomenologia da necessidade de evasão do ser, que ele identifica em alguns aspectos essenciais da existência: 


\section{RevistAleph}

- no prazer, não sendo esse uma solução para a necessidade e não tendendo a uma finalidade (encontramos confirmada, aqui, de certa forma, a concepção leopardiana do prazer);

- na imotivada vergonha de si, na qual se gostaria de fugir da identificação com o ser, do encadeamento do eu a si mesmo;

- na náusea (o texto de Levinas é anterior ao romance $A$ náusea, de Sartre, escrito em 1932, mas publicado, depois de diversas revisões, em 1938), enquanto sensação revoltante do eu pregado em si mesmo, indissoluvelmente ligado ao próprio ser e impossibilitado de sair dessa condição.

Mary Sellani: Em 1988, professor Ponzio, o senhor encontrou pessoalmente Emmanuel Levinas na sua casa em Paris. O que foi dito?

Augusto Ponzio: Relatei, no livro Alterità e identità, minha conversa com Levina, na ocasião de uma visita na sua casa, em Paris, na rua Michel-Ange, em 20 de novembro de 1988, através do título "Responsabilidade, substituição, escritura literária". Foram esses, de fato, os temas fundamentais da nossa conversa.

No que diz respeito à noção de substituição, estreitamente ligada à noção de responsabilidade, Levinas queria precisar que, no sentido em que esse termo é recorrente na sua reflexão, substituir-se não consiste em colocar-se no lugar do outro, não consiste em "colocar-se na pele do outro" para sentir o que ele sente, em uma relação de empatia, de modo que um se torne o outro, e, assim, no lugar de dois, haveria apenas um. Substituir-se é levar conforto, associando-se à fraqueza e à finitude essencial dos outros, suportar seu peso sacrificando o próprio interesse, a própria disposição-para-ser, o próprio conatus essendi. Aquilo que Levinas denomina substituição e a consequência da relação com os outros que ele indica como ética, determinando que por ética ele entende uma relação na qual um e outro não são unidos por uma síntese conceitual, nem pela relação sujeitoobjeto, mas uma relação na qual um pesa e importa, e tem um valor para o outro, na base de um emaranhado que o saber não pode resolver nem desembaraçar. Essa acepção do termo "ética" é a que Susan Petrilli e eu Ihe demos na expressão "semioética" - que dá título ao nosso livro de 2003 (Semioética, Mímesis), e dá subtítulo ao livro mencionado, de 2019, Identità e alterità. Per uma semioética della comunicazione globale [Identidade e 


\section{RevistAleph}

alteridade: por uma semioética da comunicação global] - para indicar a orientação que assume hoje a semiótica, na esteira de Charles S. Peirce, Charles Morris, Ferruccio RossiLandi e Thomas A. Sebeok, enquanto ciência geral dos signos e, portanto, da vida em todas as suas formas, enquanto semiótica global.

A relação ética, no sentido no qual Levinas emprega essa expressão, diz respeito, como já dissemos antes, ao corpo e à palavra. O corpo e seu emaranhado ético pressupõem que a palavra diga antes de tudo um contato, um envolvimento. 0 corpo permite que o dizer seja significativo independentemente do dito e que, para além da comunicação bilateral usada para a troca de mensagens, haja uma comunicação assimétrica na qual o sentido, do eu ao outro, não é indiferente e não é reversível, e na qual a distância de um dos termos ao outro não coincide necessariamente com a que separa o último do primeiro. A relação ética, nesse sentido, diz respeito à palavra também no seu sentido corpóreo: a voz, o grão da voz, a escuta, o contato, também na escritura, distinta da transcrição, sobretudo na escritura literária.

Foi esse, justamente, o terceiro tema da nossa conversa em novembro de 1988. A referência era à atenção que Levinas voltou ao "ensino filosófico" dos escritores da literatura, de Rimbaud, por exemplo, e de Baudelaire (particularmente em Levinas, L'umanesimo dell'altro uomo [O humanismo do outro homem], 1972). Essa atenção voltada, por parte de Levinas, à escritura profana e não somente à escritura sagrada, atesta que a escritura literária (seja sagrada ou profana) contribui para a possibilidade de descobrir a alteridade "au coeur même de l'identité" [no próprio coração da identidade], de reencontrar o outro no mesmo; de considerar a relação com o outro não mais em termos de diferença relativa, de pertença, de oposição e de distanciamento - a distância necessária para vê-lo, objetivá-lo, qualificá-lo.

Bari, 7 de março de 2020. 


\section{RevistAleph}

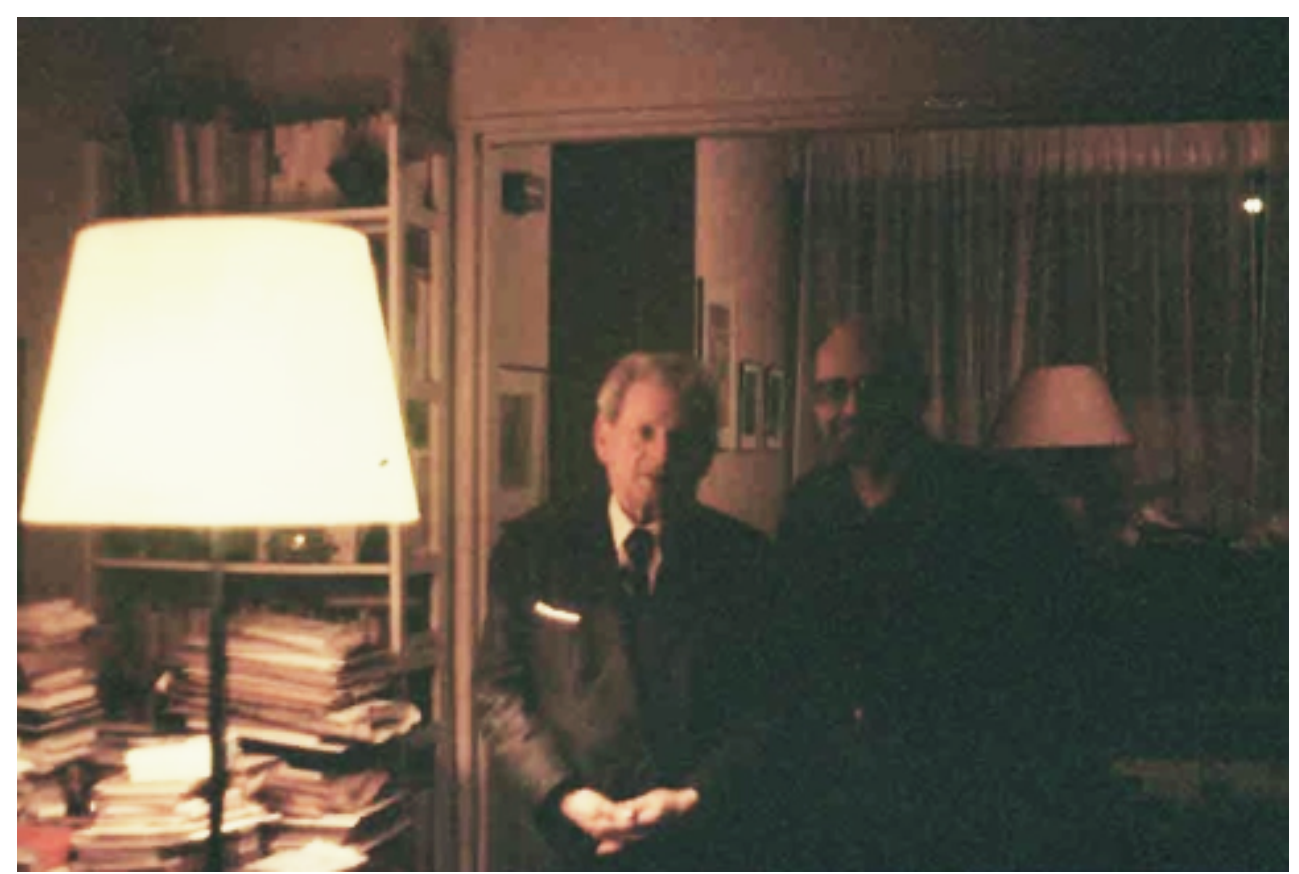

Figura 2 - Emmanuel Levinas e Augusto Ponzio, em Paris, em 20 de novembro de 1988. Fonte: Acervo pessoal do autor.

Data do envio: 07/03/2020

Data do aceite: 06/05/2020. 